\title{
Characterization of Multifloral Honeys from Angola by Their Physicochemical Parameters
}

\author{
Vanya Manolova ${ }^{1 *}$, Ivayla Parvina ${ }^{1}$, Todorka Yankovska - Stefanova ${ }^{2}$, \\ Elissaveta Luchanska ${ }^{3}$ and Ralitsa Balkanska ${ }^{4}$
}

${ }^{1}$ Central Laboratory of Veterinary Control and Ecology, Iskarsko shose Str. 5, 1528 Sofia, Bulgaria

${ }^{2}$ Bulgarian Food Safety Agency, Pencho Slaveikov Blvd. 15A, 1606 Sofia, Bulgaria ${ }^{3}$ Department of Biology, Faculty of Science, Agostinho Neto University, Luanda, Angola

${ }^{4}$ Department of Special Branches-Bees, Institute of Animal Science, Kostinbrod, Spirka Pochivka 1, 2232 Kostinbrod, Bulgaria

*Corresponding author

\section{A B S T R A C T}

The aim of the present study was to contribute to increase the current

Keywords

Honey, Physicochemical parameters, Proline, Water content, Free acidity, Electrical

conductivity, Sugars,

Diastase, Hydroxymethyl

furfural (HMF), $\mathrm{pH}$

Article Info

Accepted:

17 January 2018

Available Online:

10 February 2018 knowledge about the chemical composition of multifloral honeys from Angola through the use of main physicochemical parameters. Water content, $\mathrm{pH}$, free acidity, electrical conductivity, proline, hydroxylmethylfurfural (HMF), sugar content and diastase activity were analyzed. The mean values and standard deviations obtained for the physicochemical parameters were: water content $18.88 \pm 1.21 \%, \mathrm{pH}$ $4.36 \pm 0.59$, free acidity $29.36 \pm 13.51 \mathrm{meq} / \mathrm{kg}$, electrical conductivity $0.92 \pm 0.15 \mathrm{mS} / \mathrm{cm}$ and proline $565.77 \pm 312.39 \mathrm{mg} / \mathrm{kg}$. For all honey samples hydroxymethylfurfural (HMF) values are under $20 \mathrm{mg} / \mathrm{kg}$. The sugar content and diastase activity were also analyzed. The results obtained for multifloral honey samples from Angola indicated a good quality level according to their physicochemical parameters.

\section{Introduction}

Honey is a natural product produced by the bees and it is a nutritious food of economic importance worldwide. In the recent years, beekeeping and honey production in Africa have been increased notoriously (Maus, 2016; Moinde, 2016). This natural complex foodstuff is produced in almost every country and largely used as a food source. The honey cannot be considered as a complete food by human nutritional standards but it offers potential as a dietary supplement (Silva et al., 2009).Chemically, the honey is a complex mixture of sugars. Fructose and glucose are the main ingredients. It also contains mineral 
elements, enzymes, vitamins, volatile and some phenolic compounds as minor components (Kaskonien et al., 2010; Missio da Silva et al., 2016; Oroian and Ropciuc, 2017). It is well know that specific composition of honey depends on many factors, such as the nectar composition of the source plant, bees' species, environmental and seasonal conditions and agricultural practices (Anklam, 1998; Azeredo et al., 2003; Iglesias et al., 2012). Based on its components honey has different biological properties such as antibacterial, antiviral, anti-inflammatory, wound healing, antioxidant, radical scavenging, antidiabetic activities (Molan, 1992; Liu et al., 2013; Bogdanov, 2017). Despite of many scientific investigations into the physicochemical properties of honey, further investigations are needed in countries such as Angola where such data is insufficient.

In this respect, the aim of the present study is to contribute to increase the current knowledge about the chemical composition of multifloral honeys from Angola through the use of main physicochemical parameters.

\section{Materials and Methods}

In this study 10 honey samples from different regions of Angola (Caxito, Moxico, Viana, Catete (Bengo), Huambo, Uige, Bie) were analyzed. The honey samples are harvested by cutting the bee wax combs and put in containers. Pollen analysis was done according to Von Der Ohe et al., (2004).

According to their physical state, i.e. texture, honey samples corresponded to liquid honey. The parameters water content, hydroxymethylfurfural (HMF), $\mathrm{pH}$, proline, free acidity, diastase activity, electrical conductivity, sugars (glucose, fructose and sucrose) were analyzed according to Harmonized methods of the European Honey Commission (Bogdanov et al., 1997).
The colour intensity of honey samples was measured according to the Pfund scale. Briefly, homogeneous honey samples were transferred into cuvettes with a $10 \mathrm{~mm}$ light path until the cuvettes were approximately full. Each cuvette was inserted into a Lovibond Honey Colorpod. The colour grades were expressed in millimeter ( $\mathrm{mm})$ Pfund grades.

All reagents were of analytical reagent grade. The sugars standards (glucose, fructose and sucrose) were purchased from Fluka. Methanol (HPLC grate) and acetonitrile (HPLC grate) were purchased from Promochem.

After honeys' harvest, the samples were stored in a dark place at refrigerator $\left(2-8^{\circ} \mathrm{C}\right)$ until the analysis. All samples showed no sign of fermentation or spoilage. The results were expressed as mean \pm standard deviation. The statistical analysis was carried out using the program SPSS 21 for Windows.

\section{Results and Discussion}

Pollen analysis was used to confirm the botanical origin of the honey samples from different regions of Angola. Generally, there is not a dominant pollen type and all honey samples could be considered as multifloral. The following families and species are recognized in all honey samples: Fabaceae (Brachystegia boehmii, Brachystegia spiciformis, Erythrina abyssinica, Isoberlinia angolensis, Julbernardia paniculata, Pterocarpus angolensis); Caesalpinaceae (Bobgunnia madagascariensis, Piliostigma thonningii); Cochlospermacea (Cochlospermum angolense); Combretaceae (Combretum collinum); Sterculiaceae (Dombeya rotundifolia); Ochnaceae (Ochna schweinfurthiana); Chrysobalanaceae (Parinari curatellifolia); Polygalaceae (Securidaca longepedunculata); Myrtaceae (Syzygium 
guineense); Euphorbiaceae (Uapaca kirkiana). As a next step, the same honey samples were studied in terms of some physicochemical properties. First, the honey colour was determined. This parameter is perceived most immediately by the consumers. The honey colour can vary different from white or straw yellow to amber and from dark amber to almost black with a hint of green or red. This parameter can depend on botanical and geographical origin and also related to the mineral content, pollen and phenolic compounds present in the honey (Ramalhosa et al., 2011; El-Metwally, 2015).The results of the colour analyses were 26.50- $87.00 \mathrm{~mm}$ Pfund. Similar results are obtained for Yemeni honeys (El Sohaimy et al., 2015). Visually all honey samples did not show sign of fermentation processes.

Second, the results obtained for the main physicochemical parameters are presented in Table 1.

Water content for all samples was low with an average value of $18.88 \%$ (Table 1). This value supported the previous study for Egyptian honey samples (El Sohaimy et al., 2015). In the present study the highest moisture value came out for honey from Viana $(20.70 \%)$.

As it was expected, the all honey samples analyzed were found to have an acidic character. Their $\mathrm{pH}$ values ranged from $\mathrm{pH}$ 3.76 to 5.46 (Table 1). The highest $\mathrm{pH}$ value was obtained for honey from Moxico (Lucusse). It is well known that, the low $\mathrm{pH}$ values inhibit the presence of microorganisms. Furthermore, according to Feas et al., (2010) the values of $\mathrm{pH}$ in honey help determine its origin: flower or forest.

The free acidity varies in a large range between $7.80-45.20 \mathrm{meq} / \mathrm{kg}$. It depends on the presence of organic acids and corresponding lactones, esters and inorganic ions. According to the European Union Honey Directive (European Commission, 2002) the free acidity should be under $50 \mathrm{meq} / \mathrm{kg}$. Our results are under this limit. The high free acidity can be indicative for fermentation of sugars into organic acids (Ahmida et al., 2013).

The next parameter is electrical conductivity of the honey. It is closely related to the concentration of mineral elements, organic acids and proteins. This parameter shows great variability according to the floral origin and it is important for the differentiation of honey's floral origin (Terrab et al., 2008; Juszczak et al., 2009; Silva et al., 2009). The mean value $(0.92 \pm 0.15 \mathrm{mS} / \mathrm{cm})$ is up to $0.8 \mathrm{mS} / \mathrm{cm}$.

Different amino acids can be found in honey (lysine, histidine, arginine, tyrosine phenylalanine, threonine and isoleucine, leucine, valine and tryptophane), (Iglesias et al., 2004; Boonchiangma et al., 2015). Proline is the most important from a quantitative point of view (Kivrak, 2017). In this study, the values for proline range between 264 and $1132 \mathrm{mg} / \mathrm{kg}$ (Fig. 1). The mean value and standard deviation is $565.77 \pm 312.39 \mathrm{mg} / \mathrm{kg}$. Our results are comparable to those for multifloral honey samples from Burkina Faso (Meda et al., 2005). A great variation in the proline content $(20.8-673.3 \mathrm{mg} / \mathrm{kg})$ was also observed by Muli et al., (2007).

The diastase activity and HMF are widely recognized as parameters for the evaluation of honey freshness and overheating. The diastase activity shows very different values, ranging between 0.30 and 14.40 DN. Several factors influence the formation of $\mathrm{HMF}$, such as storage conditions (e.g. temperature). It is well known that honey heating results in the formation of HMF which is produced during acid-catalysed dehydratation of hexoses, such as fructose and glucose (Belitz and Grosch, 1999). 
Table.1 Physicochemical parameters of honey samples from Angola, $(n=10)$

\begin{tabular}{|l|l|l|}
\hline Parameters & Mean \pm SD & Ranges \\
\hline Water content, $\%$ & $18.88 \pm 1.21$ & $16.90-20.70$ \\
\hline $\mathrm{pH}$ & $3.96 \pm 0.13$ & $3.76-5.46$ \\
Free acidity, meq/kg & $29.36 \pm 13.51$ & $7.80-45.20$ \\
\hline Electrical conductivity, $\mathrm{mS} / \mathrm{cm}$ & $0.92 \pm 0.15$ & $0.76-1.25$ \\
\hline Proline, $\mathrm{mg} / \mathrm{kg}$ & $565.77 \pm 312.39$ & $264-1132$ \\
\hline Diastase activity, DN & $5.20 \pm 6.28$ & $0.30-14.40$ \\
\hline HMF, $\mathrm{mg} / \mathrm{kg}$ & $13.50 \pm 4.50$ & $10.50-19.25$ \\
\hline
\end{tabular}

Table.2 Sugar analyses of honey samples from Angola, $(\mathrm{n}=10)$

\begin{tabular}{|l|c|c|c|}
\hline Sample & Fructose, $\%$ & Glucose, $\%$ & Sucrose, $\%$ \\
\hline 1 & 37.00 & 30.00 & 0.50 \\
\hline 2 & 29.60 & 22.50 & 0.50 \\
\hline 3 & 34.90 & 30.30 & 0.80 \\
\hline 4 & 37.40 & 26.60 & 0.50 \\
\hline 5 & 36.20 & 30.80 & 0.50 \\
\hline 6 & 38.60 & 31.40 & 0.50 \\
\hline 7 & 36.20 & 31.70 & 2.13 \\
\hline 8 & 35.90 & 31.10 & 3.96 \\
\hline 9 & 38.90 & 31.10 & 0.50 \\
\hline 10 & 40.10 & 31.10 & 2.37 \\
\hline Mean \pm SD & $36.44 \pm 2.85$ & $29.66 \pm 2.90$ & $1.23 \pm 1.20$ \\
\hline
\end{tabular}

Fig.1 Box plot diagram of proline. The minimum, maximum and median values are shown

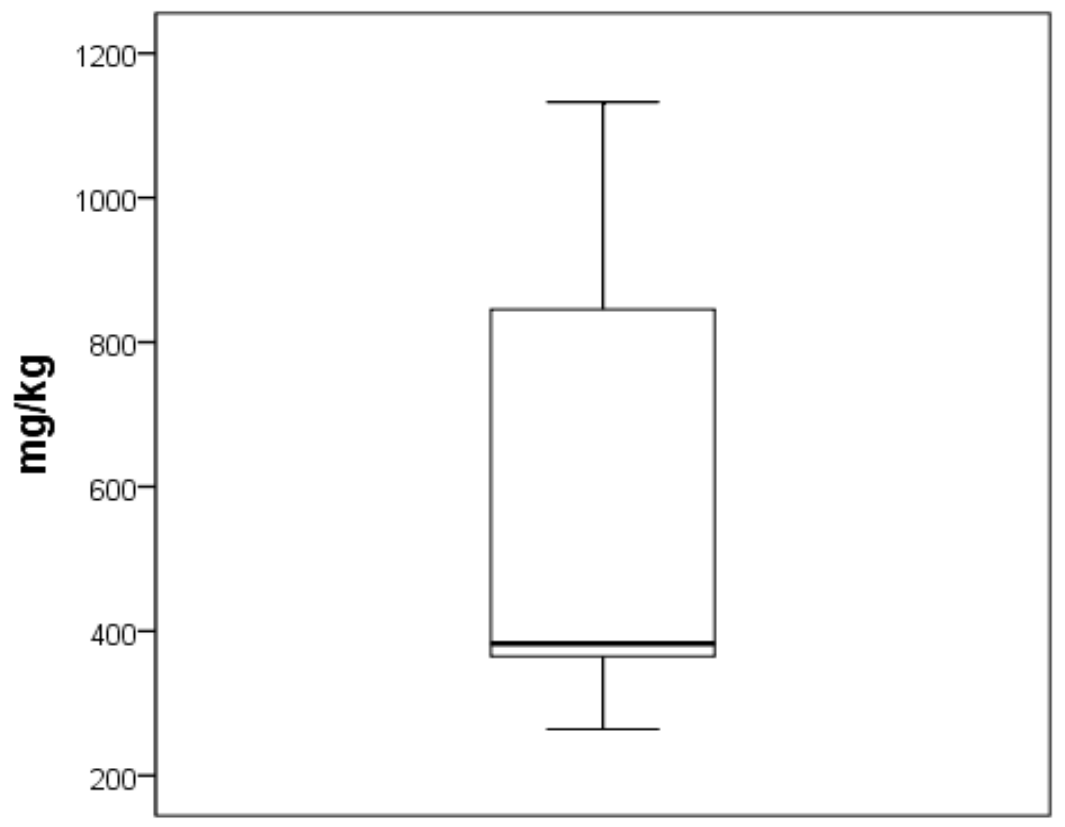


Fig.2 Chromatogram of the main sugars (fructose, glucose, sucrose) of the Angolan honey samples

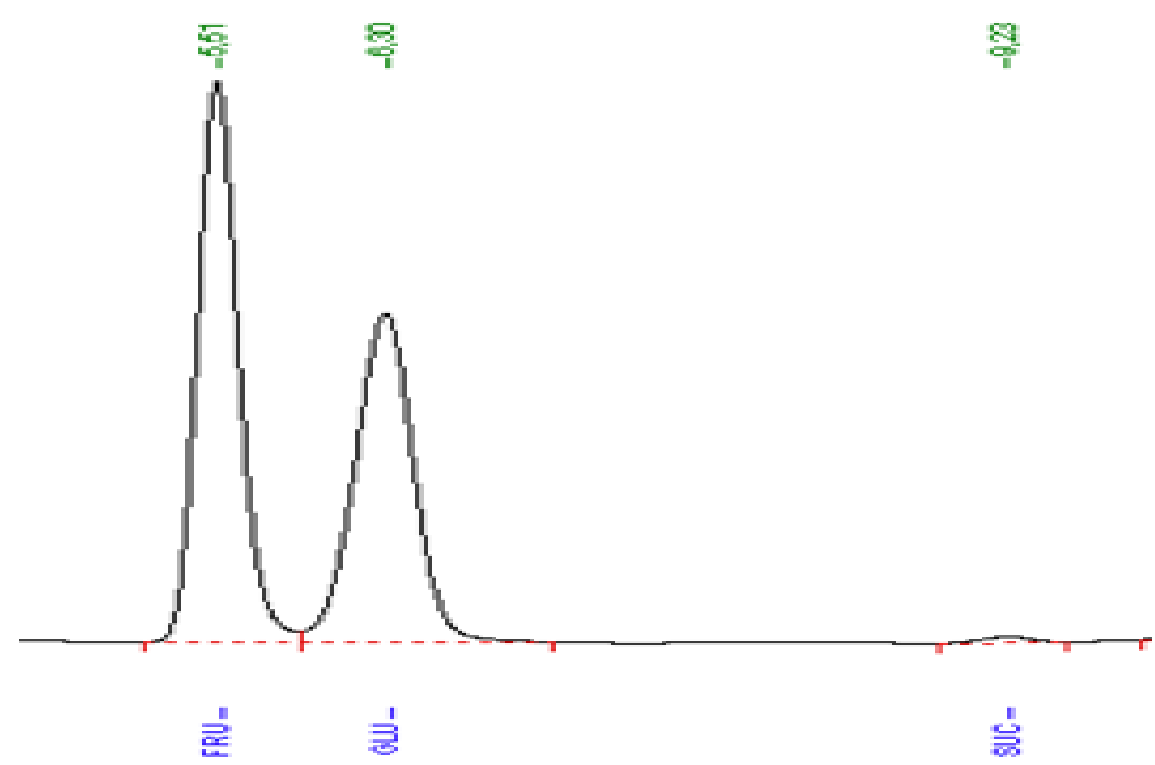

The values found fell within the European legislation corresponding to a good degree of freshness for honey samples from country with tropical climate. All samples presented HMF levels below $80 \mathrm{mg} / \mathrm{kg}$ of honey.

The average value of HMF was also low. It can be concluded that the values obtained for $\mathrm{HMF}$ and diastase activity are typical for unprocessed honey from country with tropical climate. These two parameters do not relate to the origin of the samples (Anklam, 1998).

The results for the three main sugars are presented in Table 2. All honey samples present lower values of glucose and a bit higher levels of fructose. The contents of the main sugars (fructose, glucose, sucrose) and the sum of fructose and glucose are comprised in the established confidence intervals in almost all honey samples. Indeed, only one sample presents lower sum of fructose and glucose $(52.10 \%)$. In the same manner, the sucrose content is less than 5\% for all samples (European Commission, 2002). The maximum value observed is $3.96 \%$.
HPLC chromatogram indicates that sugar composition in the tested honey samples is similar. However, some variations in the content of individual sugars are evident. Figure 2 shows the HPLC profile of one honey sample.

Fructose/glucose ratio (F/G) and glucose/water (G/W) ration were also determined. The $\mathrm{F} / \mathrm{G}$ ration was between 1.14 - 1.41 and it indicate the ability of honey to crystallize. The honey crystallization is faster when $\mathrm{F} / \mathrm{G}$ ration is below 1.0 and it slows when this ratio is up to 1.0 (Draiaia et al., 2015; El Sohaimy et al., 2015). For all obtained samples $\mathrm{F} / \mathrm{G}$ ratio is more than 1.0.Accordingly, G/W ration was between $1.14-1.83$. Honey crystallization is faster when that ratio is more than 2.0 (Amir et al., 2010). Furthermore, honey crystallization can depend on other factors such as sucrose, maltose and insoluble substance (dextrin, colloids).

Having into account the results obtained in this study, the authors consider that all 
analyzed multifloral honey samples from Angola indicate a good quality level. Special attention should be paid to the minimum value of diastase activity because some honey samples from tropical countries have much lower enzymatic activity. Much of the information hereby conveyed is completely new and with applications not only in the academic world but also in the practical life.

\section{References}

Ahmida, M.H.S., S. Elwerfali, A. Agha, M. Elagori and Ahmida, N.H.S. 2013. Physicochemical, heavy metals and phenolic compounds analysis of Libyan honey samples collected from Benghazi during 2009-2010. Food and Nutrition Sciences 4(1):33-40.

Amir, Y., A. Yesli, M. Bengana, R. Sadoudi, Amrouche, T. 2010. Physico-chemical and microbiological assessment of honey from Algeria. Electronic Journal of Environmental, Agricultural and Food Chemistry 9(9): 1485-1494.

Anklam, E. 1998. A review of the analytical methods to determine the geographical and botanical origin of honey. Food Chemistry 63: 549-562.

Azeredo, L., M.A.A. Azeredo, S.R.de Souza and Dutra, V.M.L. 2003. Protein contents and physicochemical properties in honey samples of Apis mellifera of different floral origins. Food Chemistry 80: 249-254.

Belitz, H.D. and Grosch, W. 1999. Food Chemistry. 2nd ed. Berlin, New York: Springer.

Bogdanov, S. 2017. Bee Product Science: Book of Honey, Chapter 8 Honey as Nutrient and Functional Food. Website: www.bee-hexagon.net

Boonchiangma, S., P. Ratchakru, S. Chanthai and Srijaranai, S. 2015. Reversed phase chromatographic analysis of 13 amino acids in honey samples.
Chromatographia 78: 13-14.

Draiaia, R., A. Chefrour, N. Dainese, A. Borin, C. Manzinello, A. Gallina and Mutinelli, F. 2015. Physicochemical parameters and antibiotics residuals in Algerian honey. African Journal of Biotechnology 14(14): 1242-1251.

El Sohaimy, S.A., S.H.D. Masryand Shehata, M.G. 2015. Physicochemical characteristics of honey from different origins. Annals of Agricultural Science 60(2): 279-287.

European Commission. 2002. Council Directive (2001/110/EC of 20 December 2001 relating to honey). Official Journal of European Community. L10, 47-52.

Iglesias, A., X. Feas, S. Rodrigues, J.A. Seijas, M.P. Vázquez-Tato, L.G. Dias and Estevinho, L.M. 2012. Comprehensive study of honey with protected denomination of origin and contribution to the enhancement of legal specifications. Molecules 17(7): 8568577.

Iglesias, M.T., C. De Lorenzo, M.D.C. Polo, P.J. Martin-Alvarez and Pueyo, E. 2004. Usefulness of amino acid composition to discriminate between honeydew and floral honeys. Application to honeys from a small geographic area. Journal of Agricultural and Food Chemistry 52(1): 84-89.

Juszczak, L., R. Socha, J. Roznowski, T. Fortunaand Nalepka, K. 2009. Physicochemical properties and quality parameters of herb honeys. Food Chemistry, 113: 538-542.

Kaskonien, V., P.R. Venskutonisa and Ceksteryt, V. 2010. Carbohydrate composition and electrical conductivity of different origin honeys from Lithuania. LWT - Food Science and Technology 43: 801-807.

Kivrak, S. 2017. Analysis of amino acid and phenolic content in honey by UPLC- 
ESI-MS/MS. In Honey Analysis. p. 7993. Edited by Vagner Intech.

Liu, J.R., Y.L. Ye, T.Y. Lin, Y.W. Wangand Peng, C.C. 2013. Effect of floral sources on the antioxidant, antimicrobial, and anti-inflammatory activities of honeys in Taiwan. Food Chemistry 139: (1-4): 938-943.

Maus, C. 2016. The impact on environmental stressors on apiculture in Africa. Bulletin of Animal Health and Production in Africa 64(1): 37-48.

Meda, A., C.E. Lamien, J. Millogo, M. Romito and Nacoulma, O.G. 2005. Physicochemical analyses of Burkina Fasan honey. Acta Veterinaria Brno 74: 147-152.

Missio da Silva, P.,C. Gauche, L.V. Gonzaga, A.C. Oliveira Costa and Fett, R. 2016. Honey: Chemical composition, stability and authenticity. Food Chemistry, 196: 309-323.

Moinde, J. 2016. The status and future prospects of honeybee production in Africa. Bulletin of Animal Health and Production in Africa 64(1): 169-182.

Molan, P.C. 1992. The antibacterial activity of honey. 1. The nature of the antibacterial activity. Bee World 73(1): $5-28$.

Muli, E., A. Munguti and Rain, S.K. 2007. Quality of honey harvested and processed using traditional methods in rural areas of Kenya. Acta Veterinaria Brno 76: 315-320.

Oroian, M. and Ropciuc, S. 2017. Honey authentication based on physicochemical parameters and phenolic compounds. Computers and Electronics in Agriculture, 138: 148156.

Ramalhosa, E.E., T.T. Gomes, A.P. Pereira, T.T. Dias and Estevinho, L.M. 2011. Mead production tradition versus modernity. Advanced Food Nutritional Research 63: 101-118.

Silva, L.R., R. Videira, A.P. Monteiro, P. Valentao and Andrade, P.B. 2009. Honey from Luso region (Portugal): Physicochemical characteristics and mineral contents. Microchemical Journal 93: 73-77.

Terrab, A., A.F. Recamales, D. Hernanz and Heredia, F.J. 2008. Characterisation of Spanish thyme honeys by their physicochemical characteristics and mineral contents. Food Chemistry, 88: 537-542.

Von Der Ohe, W., L. Persano Oddo, M.L. Piana, M. Morlot and Martin, P. 2004. Harmonized methods of melissopalynology. Apidologie 35: 1825.

\section{How to cite this article:}

Vanya Manolova, Ivayla Parvina, Todorka Yankovska - Stefanova, Elissaveta Luchanska and Ralitsa Balkanska. 2018. Characterization of Multifloral Honeys from Angola by Their Physicochemical Parameters. Int.J.Curr.Microbiol.App.Sci. 7(02): 1869-1875. doi: https://doi.org/10.20546/ijcmas.2018.702.225 